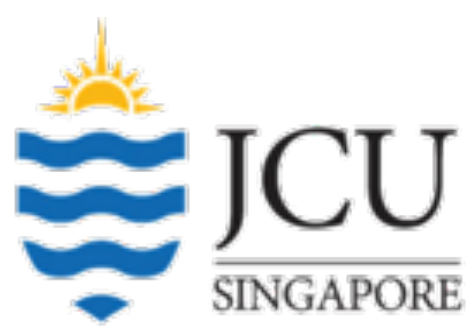

BX3052 Cross-Cultural Management Country Report

\title{
Paul French bakery expanding to Vietnam
}

May 9, 2016

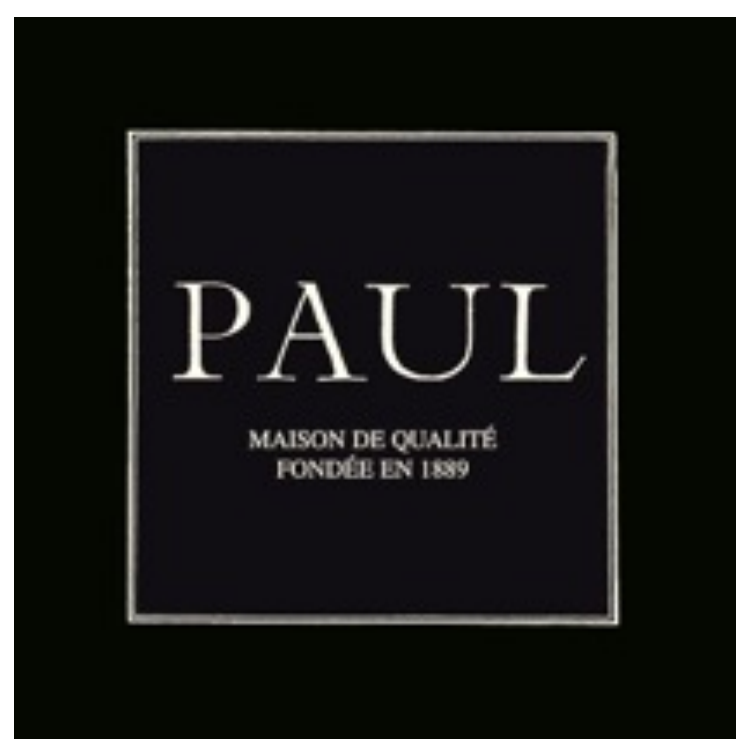

Match to Vietnam Consulting LTD.

$\begin{array}{ccc}\text { Vanessa Altrichter } & 13272700 & \text { Vanessa.altrichter@web.de } \\ \text { Sin Har What } & 13101689 & \text { Sinhar.what@my.jcu.edu.au } \\ \text { Agathe Jennequin } & 13232587 & \text { Jennequin.agathe@gmail.com }\end{array}$

Kornrarat Ngamchueachit $13113718 \quad$ Ngamchueachit@gmail.com 


\section{Table of Contents}

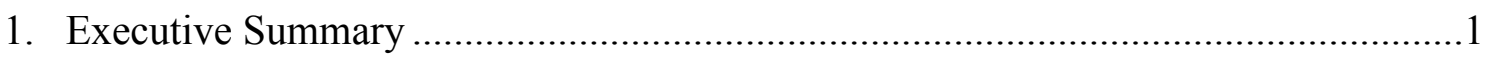

2. Brief profile of the brand Paul, France and Vietnam .............................................

2.1.Introducing Paul 2

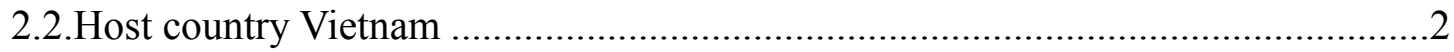

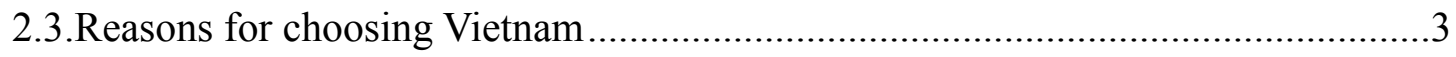

3. Key Cultural Issues and Challenges.................................................................

3.1.Issue 1: Differences in Value Dimensions..........................................................

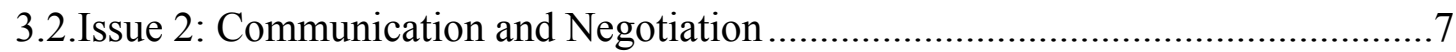

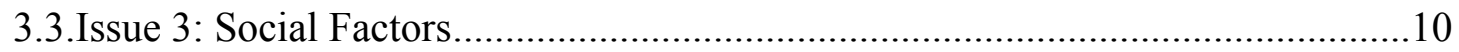

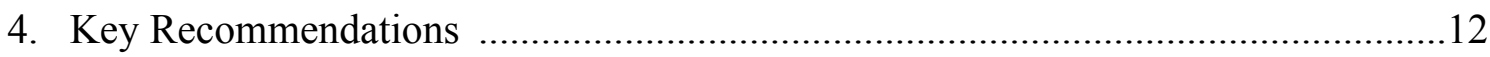

$\begin{array}{ll}\text { 5. Conclusion } & 14\end{array}$

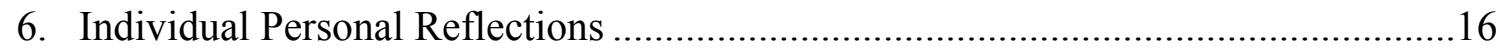

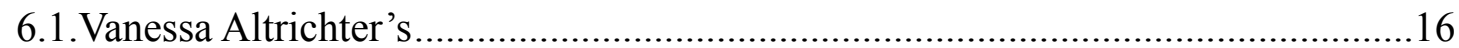

6.2.What Sin Har's 17

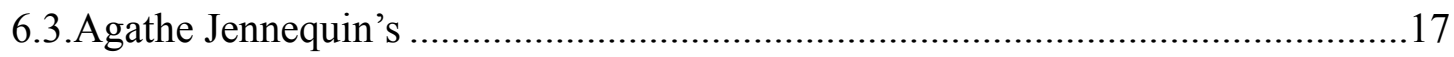

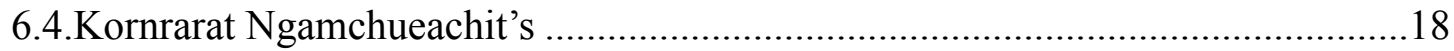

$\begin{array}{lr}\text { References } & 20\end{array}$

$\begin{array}{ll}\text { Figures } & 22\end{array}$ 

1.

Executive Summary

This report focuses on the challenges Paul would face arising from cross cultural issues when expanding from France to Vietnam. The report consists of the company's profile, an introduction into the host and home country and reasons why Paul plans to expand to Vietnam. Additionally, three main cultural issues are discussed which are challenging for the company when going abroad. When it comes to expanding abroad, it is crucial to conduct a brief PESTEL analysis about the host country in order introduce the country and to be able to analyze and understand relevant challenges. Due to favorable political, social and economic factors, which are described more precisely in the upcoming essay, it is further proven that Vietnam is a reasonable country for Paul to venture into. While using Hofstede's value dimensions, key issues about cultural differences are pointed out. The result is that the countries differ strongly in the majority of the dimensions, which need to be understood and considered by Paul.

Furthermore, the negotiation and communication style differences are analyzed carefully. When communicating, both the language itself and the negotiation style greatly differ. Vietnam practices a formal style of communication where building up a relationship is significant, whereas in French people practice a casual way of doing business and negotiating. There are further significant differences between the two countries in diet and nutrition. At the end the report gives recommendations to what extend Paul should adapt their business to the Vietnamese culture. Factors as the shop appearance, its location, the product offer, the products taste, the point of sale and the companies practiced core values may have to be differentiated in order for the business to succeed in Vietnam. 
2.

\section{Brief profile of the brand Paul, France and Vietnam}

\subsection{Introducing Paul}

Paul is a French family bakery's company built upon a foundation of time-honored production methods passed down over five generations. Paul offers four categories of high quality products which include bakery, viennoiserie, pastry and savory, costing affordable prices. Paul developed its name, built a strong reputation in Europe and is beginning to be establish a valuable brand name around the world which is known for its affordable, high quality products, heading by Maxime Holder. The core values and the companies unique selling proposition is the passion of bread, the quality of heart, the French tradition and finally the family house (PAUL, 2015). The firms priorities rely on being customer orientated, to fulfill their expectations, being respectful and last but not least strong social relations. The goal to please and respect customers is an important factor in Vietnam. Moreover, this emerging country believes in respect of rules and progress, which Paul provides. Finally, the team spirit is essential in the bakery, which is in link with the Vietnamese lifestyle.

\subsection{Host country Vietnam}

Recently, Vietnam has emerged as the second most attractive investment country in ASEAN. Indeed, it is located in a strategically beneficial position of Southeast Asia. It enjoys a competitive labor force, a political stability and a high GDP.

Vietnam is a Socialist Republic, which espouses communism, where the communist party plays a central role. Since Vietnam has adopted the new reform policy named 'Doi Moi' (Renovation), the country is becoming a politically stable. However, the government massively controls the foreign organizations entering the domestic market, which reduces their autonomy (Embassy of Vietnam, 2016). 
Since the reforms launched in 1986, Vietnam follows a more market-oriented economic model. The country is imposed as one of the fastest growing economies in the world, which high growth rates (Nga, 2013). Indeed, it allows ownership and encourages foreign investments. Vietnam key skills such as the labor force and the economic stability are increasing. The country is a part of the World Trade Organization since 2007 which had significant impacts on its economy. In addition to that, the European Union is the 3rd trade partner of Vietnam.

There are currently around 94,200,000 inhabitants in Vietnam, with a 30 years old average age, the country offers a young population enjoying an important purchasing power (Worldofmeters, 2016). This is an essential point, because even if Paul offers affordable prices, they still are more expensive than local food. Looking at the social factor, Vietnam follows the same progress than the previous aspects. The country has eradicated extreme poverty and hunger and reduced the gap between rich and poor. This emerging middle social-class is affected by westernization, which is an opportunity for our company. Even if the country is a part of globalization, it remains traditional cultures that are very different compare to foreign investor cultures, which could draw a cultural issue.

Legally, the country creates a more comprehensive framework, especially since 2007 when Vietnam has integrated the World Trade Organization. Laws and regulations have been built up in order to encourage interactions with investors in renewable energy. However, the country suffers from corruption that affects both local and foreign investors.

\subsection{Reasons for choosing Vietnam}

In Vietnam, food and beverage are one of the major industries, contributing nearly $37 \%$ of the GDP (Haivenu Co.Ltd, 2015). Eating in Vietnam is a share but functional moment. Indeed, meals are taken communally. The food is cheap, in a good quality and often served in food corners 
at the street, which is why it is very common to rather eat out than putting effort in cooking at home.

Based on a VRIO analysis, we can assume that Vietnam is a good host country choice. Vietnamese people and expatriates are inclined to eat more and more quality bread so the products are valuable, there are only a few competitors and no real traditional French bakeries. The French tradition to make breads, pastries and coffees is very difficult to imitate without a the needed know how. Paul provides, quality goods and services for low prices, which is an important competitive advantage. Moreover, the political, financial and economic stability of the country support the brand decision to expand to this market. In addition to that, since 2015, the European Union and Vietnam has signed a free trade agreement, that makes it easier for the business. Additionally, both countries share the concept of human rights and so maintain bilateral dialogue and same fundamental value. Last, it is favorable for a business that the cost for the rent and building new real estates is lower than the cost in other developed countries.

In order to expand our business in Vietnam, we intend to conduct a joint-venture. Indeed, it will provide a real agreement and trust between both countries, which is very important to success in Vietnam. This business strategy permits to access this new market for French business, share the risks and access to specialized staff, which are essential points to success in this host country.

3.

Key Cultural Issues and Challenges

\subsection{Issue 1: Differences in Value Dimensions}

In order to establish a successful business in Vietnam, Paul must take the main cultural differences in value dimensions in comparison to Singapore under consideration. After understanding and acknowledging the core differences, Paul can then evaluate to what extent they adapt their business to the countries particular needs in order to satisfy their customers. Local taste, 
preferences, buying habits can differ between the two cultures. The cultural dimensions of a society have been defined by several different models (such as from Trompenaars, Hall, the GLOBE study and Hofstede).

3.1.1. Hofstede's National Value Dimensions. When exploring culture through the lens of the six-dimension model of Geert Hofstede, an overview of the cultural differences and their impact on business in Vietnam is provided.

Professor Geert Hofstede conducted one of the most well-known and comprehensive models of how values in the workplace are influenced by culture (Xiumei Shi, 2011). He defines culture as "the collective programming of the mind distinguishing the members of one group or category of people from others". The model of national culture consists of six dimensions which represent the independent preferences for one state of affairs over another that distinguish countries (rather than individuals) from each other. A graph comparing the value dimensions of Vietnam and France can be found in the Appendix 1 (The Hofstede Centre, 2016).

Individualism. The fundamental idea of the dimension "Individualism" is the degree of interdependence a society maintains among every individual (International Business Vietnam, 2016). Whether they see themselves as a part of group who look after each other in exchange of loyalty, or rather as a single individual who mainly focuses on its family and only few other additional people. Different than in France (with a score of 71), Vietnam has a score of 20 meaning that the degree of individualism is very low and is therefore characterized as a collectivistic society. Close, long term relationships, where everyone takes care of members of their group, which go apart from just the family, is the norm (Campa, 2016). Offending an individual within a collective society can lead to shame and a loss of face. When expanding PAUL to a collectivistic society it is noticeable, that a healthy and strong Employer/employee group relationship has a significant impact 
on the business success. Remarkable is that there is not a single manager only. Every decision is being made by a group of people and thus it takes longer time to arrive at decision as people are relation, intuitive and contemplative in their decision making. This has to be taken under consideration when expanding.

Uncertainty Avoidance. The dimension Uncertainty Avoidance deals with the fact that a society never knows what the future will bring. Societies with a low UAI, feel threatened by ambiguous and unknown situations (Clearly Cultural, 2016). Here Vietnam has a low score of 30. Low UAI societies maintain a more relaxed attitude to such uncertain situations. They have no need for strict roles, forecasts or directions. Paul in Vietnam has to pay attention to the fact that the employees are willing to take risks, will face tasks form a different angle and take deadlines less serious then a French society. Vietnamese are open-minded for new innovations, changes and ideas which is beneficial when trying to successfully establish a company with western values in a country with Asian values.

Power Distance. Power Distance describes the hierarchical strength which exists between a boss and his employees within a company. It is therefore defined as the extent to which the less powerful members of a society within a country accept that power is distributed unequally (Clearly Cultural, 2016). France and Vietnam score high on this dimension (score of 70 for Vietnam, 68 for France) which means that strict hierarchical orders exist between the employer / the employees. In Hierarchy an organization managers are the decision making people. Challenges to the leadership are not well-received. Employees are not always openly expressing disagreement and do not involved in business decision-making. Information is shared infrequently and communication is formal, indirect. The management style would have to adapt when going to Vietnam being more formal and non-participative (International Business Vietnam, 2016). 
Long Term Orientation and Indulgence. The dimension "Long Term Orientation" describes the extent to which an individual of a society is tries to minimize the possible challenges arising in the future. (The Hofstede Center, 2016). Vietnam scores 57, making it a realistic and logical thinking culture. In societies with such mindsets, people believe that truth depends the circumstances of a situation, context and time. They show an ability to adapt traditions easily to changed conditions, a strong propensity to save and invest. Knowing that can have an impact when expanding the business "PAUL" to Vietnam. We can estimate that not the entire business model has to be adapted to their culture. The society is open minded for new and different food which gives PAUL the opportunity to keep the bread traditionally French. A low score of 35 in the dimension "Indulgence" on this dimension indicates that the culture of Vietnam is characterized as being discreet. Thereby they have a tendency to be pessimistic, careful and conservative (Clearly Cultural, 2016). In contrast to Indulgent societies, restrained societies have less value for leisure time and control of their lives. They believe that their actions and possibilities are limited by social norms.

\subsection{Issue 2: Communication and Negotiation}

3.2.1. Communication Style in France and Vietnam. France and Vietnam have many differences in spoken and written language. French is widely spoken and written not only in France but also in other countries in Europe. It is the fourth most widely spoken language by Europeans in the European Union (Uni, 2002). However, some French are able to communicate in English, same goes for Vietnamese. The official language used in Vietnam is Vietnamese. On the other hand, some Vietnamese can speak French, as Vietnam was part of France's colony in the past (Thecuulture, 2014). Compared to France, respecting people who are older and being polite is extremely important in Vietnamese culture. Vietnamese would prefer to address someone who is older by differently using pronouns such as "cháu" which means someone who has the same age as 
grandparent and "chị" to address someone who is younger than yourself, but this word is used by females. On the other hand, French people would like to address a person, they would call each other. The Vietnamese use indirect persuasion. "Losing face", especially in Asian countries is a main issue, which can be a result of offending or embarrassing people. Therefore, proverbs, parables or anecdotes are often used in order to make things / opinions sound nicer and less offensive. Vietnamese generally do not volunteer information or give direct feedback. If you want feedback, ask a third party familiar with your business dealings. However, opinions are never directly outspoken. Being kind and respectful while communicating is of high importance. If you must illicit comment directly from your counterpart, ask individuals politely and privately. Bad news is hard to transmit as they do not want to convey bad news or cause loss of face, so it is challenging to get explicit negative feedback. Looking for phrases or gestures that indicate nonacceptance. Positive feedback is well received if done in a low-key, private manner. Especially when problems in the business come up, it is important to never single out a Vietnamese for praise in front of others (Iorworld, 2014).

Nonverbal communication. French and Vietnamese have different types of nonverbal communication which is also known as body languages. In Vietnam, people express their feeling or emotion more indirectly madame, monsieur and mademoiselle, these way of addressing does not affiliate with the status of the listener. For example, the action of looking into somebody's eyes while talking to someone who is older or different gender indicate challenge or deep emotion. However, as believed by Vietnamese, the proper way of expressing respect to someone who is older or of different gender is to avoid eye contact.

Compared to Vietnamese, French are more direct and easy to understand in using body language or known as nonverbal communication. First of all, nodding means "Yes" and shaking 
their head means "No" which is the same as in Vietnam. However, they have a different way of saying "Hello" as in Vietnamese will just give a smile even to friends or close friends, but French will greet each other with "air kisses" on each cheek to close colleagues both males and females.

3.2.2. Negotiation Style in France and Vietnam. Building up and maintaining relationships are required for successful business. The initial meeting is viewed as a mandatory meeting to get to know one another. Talking about business related topics are not the highest priority. If a business topic comes up then only because the partner arose it.

In order to prevent cross cultural misunderstandings Paul should hire a Vietnamese speaking coordinator who will primarily be able to negotiate and translate what has been said. When closing a contract Paul needs to know that words and a hand shake are often of higher value than a written contract. Therefore, you should never commit yourself verbally unless you are willing to stand by your word. Negotiations take longer than in western countries and patience will be a necessary cross cultural attribute. When recommending a proposal to stakeholders or governmental institutions, it is recommendable to provide them a range of different possible deals so that they can consider different options.

3.2.3. Business etiquettes of Vietnam. An adequate Vietnamese business etiquette is essential to gain new partners and clients in the Vietnamese business community. Vietnamese colleagues communicate directly. Showing that you know and accept their culture is beneficial to demonstrate that you worthy their partnership. Proper behavior will directly reflect on the success of your business, as a wrong attitude can have significant negative impacts. Using the society's proper business etiquette will demonstrate both your admiration and familiarity of Vietnamese cultural practices. Additionally, it will point out your ability to be professional, to adapt and competence in an international business world. 
It is beneficial to take a local representative as a reference in order not to do any cultural mistakes. This person must be of the same sex than the main person you conduct the business with, because handshakes mainly take place between members of the same sex. In the case they are not, it is recommended you should bow. The local represent can be primordial because relationships are critical to successful business partnerships, so he can interpret and translate ideas between the both parts. At the opposite of western countries, business is based on personal lines. That is why negotiations can be slow, the time both parts know each other. To build a good relationship, business gift giving are appreciated during a meal. Then, we have to notice that the appointments are primordial and should be made weeks in advance. During them, business cards are exchanged. Moreover, you must be punctual and dress conservatively. Vietnam is a conservative country and the way your present reflect who you are. The hierarchy is essential in Vietnam, and so the most senior person should always enter the room first and sit at the extreme of the table, therefore waiting till someone asks you to enter a room and sit down is recommended. Additionally, nonverbal communication takes an important part in the Vietnamese lifestyle. You must only make promise you can keep, this is why you must consider the silence, which is common to show disagreement (Commisceo Global, 2016).

\subsection{Issue 3: Social Factors}

3.3.1. Culture. As Paul is going to be expanding into Vietnam, it is important to analyses the difference in diet and nutrition intake of the local, as this will allow Paul as a bakery to incorporate into Vietnam as something the locals would want to go to for dining. Furthermore, due to the fact that Paul originated from France, a western country which have very different diet and nutrition intake, as compared to Vietnam, an Asian country. The French are known to consume bread frequently, and in France, Paul is known for its wide range of fresh quality bread such as 
Baguette, Viennoiserie, pastry and savory sandwiches (PAUL, 2015). Similarly, Vietnamese also consume bread frequently, and likewise have a baguette which is known as Bánh mì in Vietnam. In fact, Bánh mì is of French origin, it is said to be the byproduct of French colonial period in Vietnam and Ho Chi Minh City's favorite fast lunch food. However, even though they both might look like baguette, they are actually vastly different. Compared to the French's baguette, Vietnamese Bánh mì is light, airy, and crisp due to it being more difficult to make the French's baguette in Vietnam (A. Nguyen, May 31, 2007; YOUNG, September 25, 1996). Furthermore, instead of ham, salami, lettuce and cheese as fillings for the bread, Vietnamese uses a variety of it, such as roast/smoked/ pressed pork, pork live pate, coriander and pickled carrots to name a few. This is due to Vietnamese believes that every dishes should include five basic taste senses which is link to the balance of five elements; sour(wood), sweet(Earth), salty(water), spicy metal, and bitter(fire) which in turn links to five organs, gall bladder, small and big intestine, stomach and urinary bladder. The five elements also apply to the visuals of the food, sounds of crisp from ingredient, five spices detect on the tongue (Asianinfo, 2010).

Another food that was brought in by the French and became a common consumption is coffee. The French dip their croissants and baguettes into their coffee while enjoying it in the café (Lawless, 2014). Similarly, the Vietnamese also enjoy taking their time drinking their filtered coffee while relaxing (Atexpats, 2014b). However, French coffee is served in a large cup or even a bowl with milk and can taste rather weak (Lawless, 2014). Whereas, most Vietnamese prefer their coffee to be very strong, using condensed milk instead of milk, and having their coffee beans to be deeproasted (Atexpats, 2014a; T. Nguyen, 2016). Therefore, it is recommended that PAUL ensures that each dish have a vibrant of at least five tastes, and colors by adding herbs, spices and more mix of fillings while keep to their quality French baguette recipe. It is also recommended that PAUL offer 
soya milk to go with their bread instead of milk, as Vietnam is of Asian descent which are well known to be lactose, as well as the fact that Vietnam is traditionally known to be a soya product consumer. In terms of coffee, it is recommended that they have condensed milk instead of milk and have strong favored coffee. (Atexpats, 2014a; J. Tu, March 28, 2001; V. P. Tu, Husson, Sutan, Ha, \& Valentin, 2012).

3.3.2. Religion. Although according to the national census, majority of Vietnamese consider themselves non-religious, yet most Vietnamese actually do have some system of beliefs, only that it is a disparate of Asian religious, known as tam giao: triple religion and up to $85 \%$ of them actually regularly visit Buddhist pagodas. Furthermore, according to CIA world fact book, there is also 9.3\% of the population in Vietnam considered themselves as Buddhist (Central Interlligence Agency, 1999; InsideAsia Tours, 2016). Thus, PAUL should also cater vegetarian dishes cater for the people under the Buddhist religion, which can also attract other people such as vegetarians.

3.3.3. Recreational. Although Vietnamese eat their baguette as a fast lunch, they drink their filtered coffee in a relaxed manner. Thus, it is also recommended for PAUL to have baguette to be easy to bring away along with strong favored instant coffee for take away, while having the apparatus for filtered drip coffee for those who wants to enjoy their coffee in a conducive mood (Atexpats, 2014a; J. Tu, March 28, 2001)

4. Key Recommendations

Crucial when finding the key recommendation is to primarily figure out to what extend Paul wants to adapt its business to the Vietnamese culture. There are different approaches when going abroad. They range from leaving the business model and the companies culture ethnocentric and therefore worldwide standardized or polycentric, meaning to adapt the business to the host countries culture. As Paul is emphasizing on bringing a valuable and well known French brand to Vietnam, it 
is essential to only adapt what is needed and to keep the most significant criteria which form and define a brand standardized. Therefore, the brand logo, the internal and external appearance, core values, the French flair and high quality French pastries should be maintained.

For each Marketing P; Promotion, Placement, Product and Price, the extend of adaptation has to be defined. Paul will target high end customers as producing French quality baguette and patisseries in Vietnam are expensive and accordingly will be the price. Therefore, the location has to be chosen wisely meaning next to luxury shops maybe in a high end shopping mall so that expects and people who bring money along and can afford the product will walk by. The appearance of the shop will be kept standardized to promote the French ambience and its quality. Vietnamese rather eat quickly than stay in the restaurant, so that the ordering, paying, and product receiving process must fast, seamless and adapted to this behavior. Regarding the products, it is recommended that Paul extends its product portfolio and offers diversified products. Vietnamese pay attention to colors and spices such as sours, sweet, salty and spicy. Besides soya milk in coffee has to be offered as the lactose intolerance of the majority of the Asian population is significant.

To further promote and emphasize on the French culture within the company, the employees working at Paul in Vietnam should get an introduction into the French habits, manners, values, beliefs and basic greeting vocabulary. Furthermore, the language spoken in the bakery will be Vietnamese however each customer will be greeted with the word "Bonjour" meaning "hello" in French. On the menu each product is named after the French original word. As an example "pain au chocolate" for a chocolate croissant. However, while considering the fact that the Vietnams population is afraid of losing face when being in an embarrassing situation or getting offended it is recommendable to additionally place the proper way of pronunciation and an according product 
number underneath each product name. This provides the customers three possible ways to place their order without feeling uncomfortable at any time.

It became apparent, that the fundamental base for business negotiations is to have strong and valuable connections to people within the industry and to build up long term relationship. Having a representative person who speaks the native language, knows the culture and has its connections build up is the key. Consequently, a Joint Venture with an existing Multinational bakery is beneficial. A Joint Venture represents an easy and fast way to enter a new, foreign market. Though the cooperation with a local partner, the business establishment process is accelerated, as the risk is shared, the investment is lower than investing in a fully owned subsidiary, necessary connections are already build up and Paul can benefit from the partner's business experience in the industry. It is in the interest of the Joint Venture partner that the company will be successful and therefore they will indicate possible upcoming and avoidable issues in advance.

5.

\section{Conclusion}

To conclude this report, it is essential to point out that Paul should consider the previous recommendations regarding its goods and services. Indeed, France and Vietnam are highly different 
in terms of culture and thus it is mandatory to plan strategies to shield itself from the related barriers. To increase the probability of Paul being successful in Vietnam, a cross-cultural coach who is conducting the business is of high importance. Besides that, training the chefs and product sellers could be relevant to ensure the French Paul experience is respecting the Vietnamese way of life. The coach represents a mediator between the Vietnamese and French managers, helps to solve conflicts and bring the employees from different cultures together. As the company has already expanded its brand to some parts of Asia (Singapore, Japan, Philippines, Indonesia, Taiwan and Thailand), collecting those experiences could help preventing issues. The fact that Paul has already expanded to six different Asian countries successfully shows the brands capability to adapt to different cultural needs and tastes and that it is valued by Asian societies. However, the company should pay attention to the other one it will take a joint-venture with in order to build a solid relationship. Indeed, it is essential to avoid issues like a nonreciprocal transfer of knowledge.

Finally, this country report shows how the cultural differences between two countries are vital to pay attention to when conducting a business. A misunderstanding of some etiquettes or communication can be fatal when a company wants to expand abroad. Thus, we have to keep in mind that before conducting a business overseas, we have to learn about the culture of the host country and understand their principles to success in. In this case where Paul will be expanded from France to Vietnam, we can conclude that the company should stand under the motto: "When in Rome, do as the Romans do", meaning that understand and adapt the customs of Vietnam is the best way to well expand there. 
6.

Individual Personal Reflections

\subsection{Vanessa Altrichter's}

While writing the country report Sin Har, Brooklyn, Agathe and me worked together efficiently. Agathe being from France, Brooklyn from Thailand, Sin Har from Singapore all of us were coming from different cultural backgrounds, with different values, a different mindset, believes and different point of views. This constellation was a challenge as none of us have known each other before. On the other side the constellation facilitates constructive discussions. Thus the issue of Paul expanding to a foreign market could have been reflected from every possible point of view. Each team member was highly motivated and added value to the report by their personal experience, their research, and even through asking locals of the host country. Since I was the team leader my task was to primarily distribute the work equally, to offer support in case of difficulties, to then collect the data, check its validity and add further improvements. Besides that, I was concentrating on writing about the Hofstede's value dimensions, the key recommendations, the executive summary and the negotiation styles.

The fact that we were finished with the report $2 \frac{1}{2}$ weeks in advance showed how effective the team worked together. I learned that working together in a team with members from different cultures can be challenging but works seamlessly, if you are patience, say your opinion, take part at discussions and support each other. Regarding the country report in particular, I've learned that more things that I've had expected have to be taken under consideration. It became apparent that it is crucial for every company to first clearly define which brand message they want to establish abroad so that accordingly the business model can be either left globalized, standardized and ethnocentric, or adapted to the host country. 


\subsection{What Sin Har's}

One of the most challenging encounters would definitely being thrown into a group that I practically knows no one in there, further fueled by the fact that everyone are from different countries background which would have brought on difficulties, such as something as basic as communication due to different mother tongue which might brought on accent that could be difficult to understand. Thankfully, everyone was easy to understand and was confident with their speech, allowing discussions to happen and not one sided which I had experienced in another module where no one wants to discuss. The group is also highly motivated, during the first day of the group creation we had already decided on the company we wanted to work on and had ideas on what we could talk about. However, we realize that by using that company it might make the context confusing and difficult to work with. Even then that did not hinder us and we quickly found another company to work on.

The negative reflection about myself would be the fact that I would always put myself as a science student first instead of a business student, despite taking a degree that is based on both science and business, this makes me feel unconfident and inferior when talking about business subjects making me not to speak up at times and just go with the flow, easily change my decisions when it is important despite my opinion.

\subsection{Agathe Jennequin's}

I enjoyed working on the topic Paul expanding from France to Vietnam. We worked efficiently and hard on it, and met every week at least once. I appreciated to work with Vanessa, Sin Har and Brooklyn because they are reliable team members and friendly persons. 
In my point of view, I am satisfied with the work I have delivered and hope that the team I have worked with could easily rely on me. With the leader Vanessa, we managed to divide the work efficiently and in similar parts. I have played an important role on this topic because I am the French one linked with the brand Paul. Because of this and my previous experience as a manager, I felt like a sub-leader, trying to provide my help for who needed and checking the work of each team members with the leader. My team was international, composing with Vanessa from Germany, Sin Har from Singapore and Brooklyn from Thailand. I have learnt about handling the different ways of working and understanding the different attitudes towards work. Personally, this was the most enriching part of this experience. I have learned about topics in link with our work, but also about Germany and especially Singapore and Vietnam, which is, I think, also part of a Cross Cultural Management lecture. Additionally, I was surprised to understand how cultures are important to consider when conducting a business abroad. It was very interesting to see the different value dimensions between my home country, and Vietnam. This was possible thanks to the freedom we have to select both the company and the host country, and I think it is also a factor of my involvement because I felt concerned and interested in the topic. From this assignment, I have learnt to build a trust atmosphere between the team to success, and deal with a group work with people from different nations, which was the most challenging task in my opinion.

\subsection{Kornrarat Ngamchueachit's}

In Cross culture management (Bx 3052), my group and I were required to produce a country report and a presentation about the culture differences between the countries. We have chosen France and Vietnam as the countries. During the first tutorial, we was divided into a group of four people where my group have four people from different countries such as France, Germany, 
Singapore and Thailand. Moreover, this is my first time working as a group with people that have different cultures and speak different languages.

Personally, I have gained a lot of experiences in working as a team and it was challenging as well as interesting. The collaboration in my group went well as all members could communicate and clarify all problems through various channels like Whatsapp, Facebook and we also had a meeting every week after each tutorials. The leader was Vanessa who dIvided works for us. Vanessa and Agathe also helped me with my part as I was struggling with writing the Business etiquettes of Vietnam and the negotiation of both countries.

Moreover, I did not speak up a lot during tutorials and discussions time and sometimes I posted my work late due to other assignments from other, so that would be the negative reflection about myself.

From doing this report, I have learnt a lot of things such as the cultures difference between the two countries, Harris and Moran's model, Hofstede cultural dimension model. I also got to know many new people from my group and outside my group. I have learnt to work as a team and interact and collaborate with others. 
References

Asianinfo. (2010). Vietnamese Food. Retrieved from http://www.asianinfo.org/asianinfo/vietnam/ pro-food.htm

Atexpats. (2014a, 10.15.2014). Ca Phe Sua Da. Retrieved from http://www.atexpats.com/ magazine/553-ca-phe-sua-da.html

Atexpats. (2014b, 10.15.2014). The Story of Coffee. Retrieved from http://www.atexpats.com/ magazine/555-the-story-of-coffee.html

Campa, D. M., \& Martínez, V. B. Stability of Collectivism and Individualism in Vietnamese Americans and Mexican Americans.

Central Interlligence Agency. (1999). THE WORLD FACTBOOK Vietnam. Retrieved from https://www.cia.gov/library/publications/the-world-factbook/geos/vm.html

Ching, A. C. C., Lee, C. A., Ean, C. S., Wai, D. P. K., Leng, H. C., Min, R. Y. H., \& Seevinash. (2013). Non-Verbal Communication In France. Retrieved from http:// bcplgn012.blogspot.sg/2013/05/non-verbal-communication-in-france.html

Clearly Cultural. (2016). Geert Hofstede cultural dimensions. Retrieved from http:// www.clearlycultural.com/geert-hofstede-cultural-dimensions/

Commisceo Global. (2016). Vietnam Guide. Retrieved from http://www.commisceo-global.com/ country-guides/vietnam-guide

Debating Europe. (2014). Should English be the only official language of the EU? Retrieved from Should English be the only official language of the EU?

Embassy of Vietnam. (2016). CONSTITUTION AND POLITICAL SYSTEM. Retrieved from http://vietnamembassy-usa.org/vietnam/politics

Haivenu Co.Ltd. (2015). Vietnamese cuisine, traditions and etiquette. Retrieved from http:// www.haivenu-vietnam.com/vietnam-culture-food.htm

Holidays Vietnam. (2014). Vietnam Verbal Communication. Retrieved from http:// www.holidaysvietnam.com/travel-guide/vietnam-verbal-communication.html

InsideAsia Tours. (2016). Religion in Vietnam. Retrieved from https://www.insideasiatours.com/ insidevietnam/vietnamese-culture/religion/

International Business Vietnam. Hofstede's Power Distance. Retrieved from http:// internationalbusinessvietnam.weebly.com/hofstedes-power-distance.html

Lawless, L. K. (2014). French Coffee - Ordering Coffee in France. Retrieved from http:// french.about.com/od/vocabulary/a/coffee.htm

Moonen, E. (Producer). (2012). Verbal and Non-verbal Communication. Retrieved from https:// prezi.com/o2jxcb60hdqp/verbal-and-non-verbal-communication/

Nga, N. V. (2013). Vietnam's Youth Environmental Movement Takes Off. Retrieved from http:// asiafoundation.org/in-asia/2013/06/26/vietnams-youth-environmental-movement-takes-off/

Nguyen, A. (May 31, 2007). Vietnamese Baguette Recipe (Banh Mi Tay). Retrieved from http:// www.vietworldkitchen.com/blog/2007/05/vietnamese bagu.html

Nguyen, T. (2016). Welcome to Trung Nguyen Online! Retrieved from http://www.trung-nguyenonline.com/

Passport to Trade 2.0. (2014). Business communication. Retrieved from http://businessculture.org/ western-europe/business-culture-in-france/business-communication-in-france/

PAUL. (2015). PAUL soutient Maans enFete. Retrieved from http://www.paul.fr/fr/

PAUL, S. (2015). PAUL depuis 1889. Retrieved from http://www.paul.fr/en/content/7-our-values 
TEAM EDV. (2010). Lesson 9: When Speaking Vietnamese, How To Address Others. Retrieved from http://www.everydayviet.com/video/lesson-9-when-speaking-vietnamese-how-toaddress-others/

the hofstede centre. What about France. Retrieved from https://geert-hofstede.com/france.html

The hofstede centre. (2016). National Culture. Retrieved from https://geert-hofstede.com/nationalculture.html

The World Bank Group. (2016). Overview. Retrieved from http://www.worldbank.org/en/country/ vietnam/overview

Tu, J. (March 28, 2001). Nutrition and Fasting in Vietnamese Culture. Retrieved from https:// ethnomed.org/clinical/nutrition/viet-food

Tu, V. P., Husson, F., Sutan, A., Ha, D. T., \& Valentin, D. (2012). For me the taste of soy is not a barrier to its consumption. And how about you? Appetite, 58(3), 914-921. doi:http:// dx.doi.org/10.1016/j.appet.2012.01.023

Viet Nam News. (2014). No time to lose for climate change action. Retrieved from http:// vietnamnews.vn/environment/261509/no-time-to-lose-for-climate-change-action.html

Vuong, Q. H., \& Tran, T. D. (2009). The cultural dimensions of the Vietnamese private entrepreneurship. The IUP Journal of Entrepreneurship and Development, 6(3), 54-78.

Worldofmeters. (2016). Viet Nam Population (LIVE) Retrieved from http:// www.worldometers.info/world-population/vietnam-population/

Young, D. ( September 25, 1996). East meets West in 'Nam Sandwich France's influence on Indochina helps to Baguette Viet Fave. Retrieved from http://www.nydailynews.com/ archives/lifestyle/east-meets-west-nam-sandwich-france-influence-indochina-helpsbaguette-viet-fave-article-1.742637 
Figures

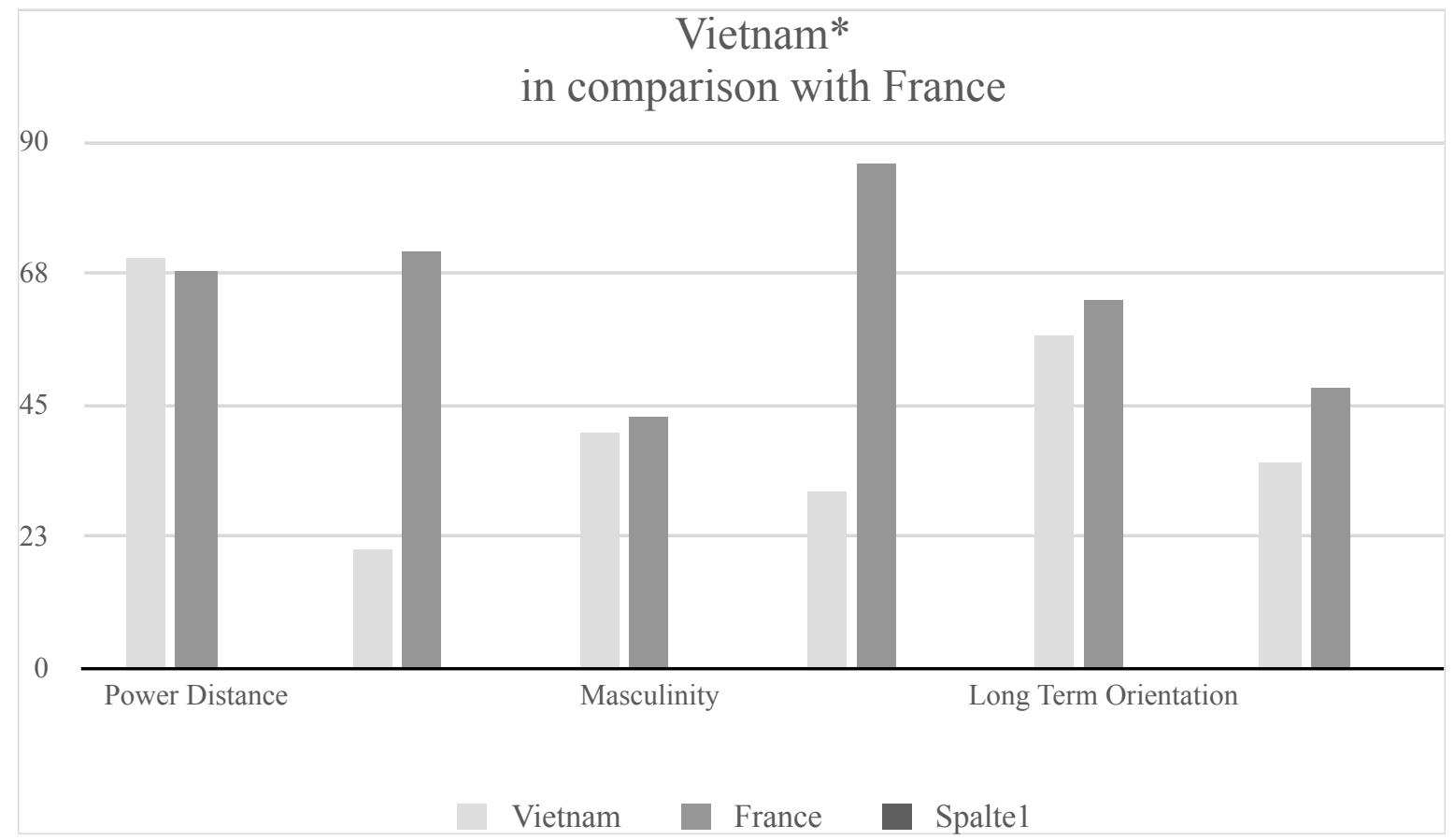

Figure 1: Hofstede's National Value Dimensions, comparison of Vietnam and France (the hofstede centre) 
